\title{
ЛАТЕНТНЫЙ АУТОИММУННЫЙ САХАРНЫЙ ДИАБЕТ В ДЕТСКОМ ВОЗРАСТЕ
}

\section{Бричева Э.Б., Еремина И.А., Романенкова Е.М.}

ФГБУ «Национальный медицинский исследовательский центр эндокринологии» Минздрава России

Латентный аутоиммунный сахарный диабет (СД) - заболевание, при котором, несмотря на присутствие панкреатических аутоантител при диагностике заболевания, отмечается медленное снижение собственной секреции инсулина $\beta$-клетками и отсутствует потребность в назначении инсулинотерапии, по крайней мере, в течение первых 6 месяцев после постановки диагноза. Большинство случаев латентного СД описано у взрослых пациентов (LADA - Latent autoimmune diabetes in adults) с фенотипом СД 2 типа.

Клинический случай: Пациентка П., 14 лет, поступила в отделение с направляющим диагнозом: сахарный диабет 2 типа. С 3,5 лет у девочки наблюдался избыточный набор массы тела прогрессирующего характера. С 12 лет по поводу экзогенно-конституционального ожирения пациентке была назначена терапия метформином (1000 мг/сут), которую девочка принимала нерегулярно. В 14 лет, в связи с выявлением повышенного уровня гликированного гемоглобина (6,5\%), был установлен диагноз «Сахарный диабет 2 типа», доза метформина увеличена до 2000 мг/сут.

Наследственность отягощена: ожирение у отца и дедушки по материнской линии, СД 2 типа у бабушки по материнской линии и прабабушки по отцовской линии.

Спустя 2 месяца после диагностики СД девочка поступила в ФГБУ «НМИЦ эндокринологии» М3 РФ. При осмотре: рост 173,6 см (SDS 1,89), вес 155 кг, ИМТ 51,4 кг/м2 (SDS 4,38), Таннер 4 (В 4, Р 5) менструации с 11 лет, нерегулярные. Кожные покровы с явлениями слабовыраженного acantosis nigricans в подмышечных впадинах и на задней поверхности шеи, множественные бледно-розовые стрии на груди, животе, боковых поверхностях туловища, плечах, бедрах, пояснице, гирсутизм по шкале Ф.Голлвея - 2 балла. Подкожно-жировая клетчатка развита избыточно, распределена равномерно. АД 138/80 мм.рт.ст., ЧСС 71 уд/мин. НbА1c - 6,3\%. Выявлено повышение уровня мочевой кислоты $(418,9$ мкмоль/л $(120,0-320,0))$ и холестерина ЛПНП $(3,31$ мкмоль/л $(1,10-3,00))$. На фоне 3-х дневной отмены метформина проведен ПГТТ: уровень гликемии натощак 5,01 ммоль/л, на 30 мин - 9,28 ммоль/л, на 60 мин - 13,8 ммоль/л, на 90 мин - 13,33 ммоль/л, на 120 мин - 12,21 ммоль/л; уровень инсулина натощак - 45,14 мкед/мл, на 30 мин - 96,91 мкед/л, на 60 мин - 164,8 мкед/мл, на 90 мин - 177,4 мкед/мл, на 120 мин - 153,2 мкед/мл. Индексы инсулинорезистентности: НОМА 10,05 (норма <3,2); Matsuda 1,0 (норма >2,5). Специфические панкреатические аутоантитела: IA-2 - 358,1 Ед/мл; GADA - 2000 Ед/мл, ZnT8 - 500 Ед/мл. По данным УЗИ - эхографические признаки гепатомегалии, жировой дистрофии печени, диффузных изменений поджелудочной железы; патологии органов малого таза не выявлено. Гормональный анализ крови (ТТГ, Т4 своб, ЛГ, ФСГ, эстрадиол, тестостерон, ДГЭА-С) без отклонений от нормы. Кардиологом установлена лабильная артериальная гипертензия.

За время пребывания в стационаре при исследовании гликемического профиля в 9 точках наблюдались колебания гликемии в пределах от 4,1 до 11,7 ммоль/л. В течение последующих 2 месяцев в домашних условиях сохранялись удовлетворительные показатели гликемии.

Заключение: У пациентки с выраженным ожирением и признаками метаболического синдрома (сахарный диабет, гиперинсулинемическая инсулинорезистентность, дислипидемия, гиперурикемия, артериальная гипертензия, жировой гепатоз) выявлен высокий титр специфических панкреатических аутоантител, что позволяет диагностировать у нее СД 1 типа. Учитывая удовлетворительные 
показатели гликемии в течение дня, целевой уровень гликированного гемоглобина, высокую собственную секрецию инсулина, показаний для инициации инсулинотерапии не было.

Данный клинический случай описывает латентное течение аутоиммунного сахарного диабета у девочки-подростка на фоне выраженного ожирения. Интересно, что диабетический уровень гликемии и гликированного гемоглобина диагностирован на фоне высокой эндогенной секреции инсулина, что обычно наблюдается при СД 2 типа. Подобное течение СД в настоящее время предлагается рассматривать как двойной диабет. В литературе встречается также использование терминов «латентный диабет молодых» (LADY), диабет 1,5.

При исследовании спектра панкреатических аутоантител у взрослых пациентов с латентным аутоиммунным сахарным диабетом наиболее часто и в более высоком титре выявлялись антитела к глутаматдекарбоксилазе. В описанном нами случае также выявлен крайне высокий титр данного вида антител и значимое повышение титра антител к тирозинфосфатазе и транспортеру цинка.

Данный клинический случай подчеркивает необходимость исследования панкреатических аутоантител у всех детей с впервые выявленным СД на фоне ожирения, даже при типичной клинической картине СД 2 типа. 